\title{
Evaluation of the health promotion behavior in patients with diabetes mellitus*
}

\author{
Avaliação do comportamento de promoção da saúde em portadores de diabetes mellitus \\ Evaluación del comportamiento de promoción de la salud en portadores de diabetes mellitus
}

\author{
Francisca Aline Arrais Sampaio1, Renata Pereira de $\mathrm{Melo}^{2}$, Isaura Letícia \\ Tavares Palmeira Rolim ${ }^{1}$, Ricardo Costa de Siqueira ${ }^{3}$, Lorena Barbosa Ximenes ${ }^{4}$, \\ Marcos Venícios de Oliveira Lopes ${ }^{5}$
}

\begin{abstract}
Objective: To evaluate the health promotion behavior of diabetic patients in agreement with the indicators of the Nursing Outcome Classification (NOC). Methods: A cross-sectional study was performed with 84 diabetic patients followed in a Basic Health Unit, using the NOC scale for health promotion behavior. Results: Among the appraised indicators, the use of social support for health promotion and the development of health behaviors presented median $\leq 2$. The health promotion behavior presented median $=3$. Conclusion: Diabetic patients present limitations to the practice of health promotion behavior.
\end{abstract}

Keywords: Health promotion, Diabetes mellitus; Outcome assessment (Health Care); Quality indicators, health care

\section{RESUMO}

Objetivo: Avaliar o comportamento de promoção da saúde de portadores de diabetes de acordo com os indicadores da Classificação dos Resultados de Enfermagem (NOC). Métodos: Um estudo transversal realizado com 84 diabéticos acompanhados numa Unidade Básica de Saúde, sendo utilizada a escala NOC para o comportamento de promoção da saúde. Resultados: Dentre os indicadores avaliados, o uso de apoio social para promoção da saúde e o desempenho de hábitos de saúde apresentaram mediana $\leq 2$. O comportamento de promoção da saúde apresentou mediana $=3$. Conclusão: Os diabéticos apresentam limitações quanto à prática de comportamento de promoção de saúde. Descritores: Promoção da saúde, Diabetes mellitus; Avaliação de resultados (Cuidados de Saúde); Indicadores de qualidade em assistência à saúde

\section{RESUMEN}

Objetivo: Evaluar el comportamiento de promoción de la salud de portadores de diabetes de acuerdo a los indicadores de la Clasificación de los Resultados de Enfermería (NOC). Métodos: Se trata de un estudio transversal realizado con 84 diabéticos de una Unidad Básica de Salud, siendo utilizada la escala NOC para el comportamiento de promoción de la salud. Resultados: De los indicadores evaluados, el uso de apoyo social para la promoción de la salud y el desempeño de hábitos de salud presentaron mediana $\leq 2$. El comportamiento de promoción de la salud presentó mediana $=3$. Conclusión: Los diabéticos presentan limitaciones en cuanto a la práctica de comportamiento de promoción de la salud.

Descriptores: Promoción de la salud, Diabetes mellitus; Evaluación de resultados (Cuidados de Salud); Indicadores de calidad en la asistencia a la salud

\footnotetext{
*This study was performed as part of the class "Nursing and the theoretical foundations of health promotion" of the Nursing Graduate Program at the Universidade Federal do Ceará - UFC - Fortaleza (CE), Brazil.

${ }^{1}$ Master Degree from Universidade Federal do Ceará - UFC - Fortaleza (CE), Brazil.

${ }^{2}$ Graduate at the Universidade Federal do Ceará - UFC - Fortaleza (CE), Brazil.

${ }^{3}$ Master Degree in Nursing from Universidade Federal do Ceará - UFC - Fortaleza (CE), Brazil.

${ }^{4}$ Associate Professor of the Nursing Department of Universidade Federal do Ceará - UFC - Fortaleza (CE), Brazil

${ }_{5}$ Associate Professor of the Nursing Department of Universidade Federal do Ceará - UFC - Fortaleza (CE), Brazil
} 


\section{INTRODUCTION}

Diabetes Mellitus (DM) is a chronic disease that affects around 194 million people worldwide ${ }^{(1)}$. It is responsible for approximately 346 thousand new cases in individuals over 40 years old, in addition to the 11 million existing cases, according to a search performed by the Health Ministry in Brazil during the National Campaign for the Detection of Diabetes in $2001^{(2)}$.

Although the DM diagnosis is easy and relatively inexpensive, thousands of individuals in Brazil are still unaware that they are have diabetes. It is the major cause of acquired blindness, inferior limb amputation without a trauma situation, and renal failure in the Dialysis Program. Furthermore, it causes $6 \%$ of all deaths and is responsible for $30 \%$ of ICU hospitalizations ${ }^{(3)}$.

Providing health care to patients with a chronic disease becomes a challenge, because besides counting on the support from the health sector, it also requires participation from the family and the patient. The latter has the main role in the search of his/her full health ${ }^{(4)}$. Therefore, the idea of promoting health has been discussed as a proposition and strategy for improving health conditions, involving a process to capacitate the community with a view to improve their health and quality of life, including their participation and control over this process $^{(5)}$.

Since DM demands effective self-care skills from the patient, the nursing professional should consider the client's particularities when planning care, in order to find, with the patient, and through a detailed behavioral evaluation, proper health promotion measures.

Therefore, in order to reach a high level of health, by encouraging patients to adopt healthy habits, the individuals' personal internal or external factors should be considered, such as their behavior in health or disease situations, their perception of previous experiences or even the control they have over their own lives ${ }^{(6)}$.

In this sense, the purpose of this study was to evaluate the Health Promotion Behavior in patients with DM, according to Nursing Outcomes Results - NOC indicators $^{(7)}$.

\section{METHODS}

This is a cross-sectional study developed at a Basic Family Health Care Unit, performed with subjects, of both genders, and with DM. Clients with gestational diabetes and/or any other disease that led to a temporary alteration of glycemia and morbidities associated to DM were excluded from the study.

The sample consisted of 84 individuals with a confidence coefficient of $95 \%\left(Z_{a}=1.96\right)$, a population (N) comprised of 242 clients with DM, who were registered and followed at the health unit, sample error (E) of $5 \%$, and a prevalence (P) of $9 \%$ extracted from a previous study ${ }^{(8)}$.

The studied population was followed by five independent health teams. For this reaon, the sampling process was random, stratified, and proportional. Thus, there were 16 individuals in team $1 ; 21$ in team $2 ; 18$ in team 3; 17 in team 4 , and 12 in team 5 .

Data collection was performed during home visits using a form covering the patient's gender, age, clinical indicators, and indicators associated to health behavior for DM.

The obtained clinical data were: time of diagnosis, capillary glycemia, previous hospitalization due to glycemia alteration, physical impairment associated to motor and tactile functions, visual impairment, drug treatment, and comorbidities. The section addressing health behavior was designed based on the nursing result Health Promotion Behavior, described in the NOC.

Based on the referred NOC results, some health indicators were selected, such as: "Uses risk avoidance behaviors", "Monitors personal behavior regarding the risks", "Searches balance among exercise, work, leisure, rest and nutrition", "Performs health habits correctly" and "Uses social support to promote health habits" and "Uses social support to promote health".

Operational definitions, based on scientific literature on the theme $e^{(2,7,9-11)}$, were established for each indicator. Therefore, the indicator "Uses risk-avoidance behaviors" was evaluated with the items: "Keeps ideal weight for height", "Performs dynamic physical exercises", "Eats properly", "Does not drink alcoholic beverages", "Keeps blood pressure at satisfactory levels" and "Takes antihyperglicemic or other medication correctly when having concomitant health issue".

The indicator "Monitors personal behavior regarding risks", included the following characteristics: "Monitors blood pressure", "Monitors glycemia", "Checks weight", "Performs check-ups with a health professional", "Performs ophthalmological check-ups" and "Performs foot care".

The indicator "Searches balance among exercise, work, leisure, rest and nutrition" was organized considering the individual's day-by-day activities. The activities were rated according to their relevance for the glycemia control. Thus, nutrition scored 5, physical exercise 4, leisure 3, rest 2, work 1 . These scores were added up and interpreted according to the following ranges: 1 to 2 points level 1 in the original scale; 3 to 5 level 2; 6 to 9 level 3; 10 to 14 level 4; and 15 level 5 in the scale.

It is important to state that exercise was considered adequate when performed at least three times a week, for at least 30 minutes, for individuals with normal weight and normal blood pressure, or for at least 50 minutes if 
obese and/or borderline hypertensive ${ }^{(9)}$. Nutrition was considered adequate when not consuming sugar and sweets, using sweeteners instead, as well as avoiding sodium in food, and eating fruit and vegetables regularly ${ }^{(10)}$.

The indicator "Performs health habits correctly" had as items "Keeps ideal weight for his/her height", "Performs dynamic physical exercises", "Eats properly", "Does not drink alcoholic beverages", "Keeps blood pressure in tolerable levels" and "Takes anti-hyperglicemic or other medication correctly when having concomitant health issue". The item "Takes anti-hyperglicemic or other medication correctly when having concomitant health issue" was considered only in those cases where medications were regularly administered.

Finally, the indicator "Uses social support to promote health" was evaluated considering the following items "Family", "Support group", "Community" and "Health unit (primary care)", according to the number of structures used by the individual in his/her social or support group. In other words, the more groups the individual was in, the higher the scale item was valued.

Therefore, the general evaluation for the Result "Health Promotion Behavior" was done using a scale that comprehended all possible values found in the final adding of all items previously described. These values were organized in the following ranges: 5 to 8 points health promotion behavior never shown; 9 to 12 points - health promotion behavior rarely shown; 13 to 16 points - health promotion behavior sometimes shown; 17 to 20 points - health promotion behavior usually shown; and 21 to 25 points - health promotion behavior considerably shown.

The data were stored in an Excel spreadsheet and were analyzed using the Statistical Package for Social Sciences (SPSS) 13.0, enabling the organization of dicotomic and categorical variables in tables with their absolute and relative frequencies. The numeric variables were presented according to their central tendency measures (mean and median) and dispersion (standard deviation). Some variables were not totally registered due to physical impairment or even for the participant's choice to not answering.
The study was submitted to the appreciation and approval of the local Research Ethics Committee. The ethical precepts of non beneficence, of non malfeasance, as well as the right of anonymity of the participant and his/her will of refusing to participate in the research without any harms, according to the n. ${ }^{\circ} 196 / 96$ Resolution of the National Council in Research Ethics.

\section{RESULTS}

As shown in Table 1, below, the sample consisted mainly of women, with an approximate ratio of 3:1. The average age was of 63.4 years, minimum 21 and maximum 96. (Table 1)

Regarding education, although the sample included one person with 14 years of education, this value did not affect the reduced average of 4.36 years of education; there were individuals in the study without any education at all. The average time of diagnosis was 7.25 years, but it does not correspond to the exact time of the health issue onset since diabetes type 2 , which prevailed in the studied sample, is usually detected around 4 to 7 after its development ${ }^{(11)}$. The median and mean glycemia values were considered hight, with values of $167 \mathrm{mg} / \mathrm{dl}$ and $193 \mathrm{md} / \mathrm{dl}$, respectively.

Based on BMI indexes, the obtained average score was 27.79 , which characterizes overweight. The average diastolic blood pressure (DBP) was approximately $145.32 \mathrm{mmHg}$. It should be notices that 50 percent of the DBP values was $87 \mathrm{mmHg}$, this shows that at least half the sample presented DBP above normal values.

According to Table 2, the indicator "Uses riskavoidance behavior", representing the identified health condition and behavior for maintining it, had a positive result, with median 4 . It indicated that half the sample had these health behavior patterns "consecutively".

The indicator "Monitors personal behavior regarding risks", which included activities regarding control, follow-up, and care towards health maintenance or promotion, presented central value with median around 3. It indicated that at least half the sample "sometimes" monitored their behavior regarding risks.

Among the activities performed by the sample, from

Table 1 - Sample distribution according to personal identification, socioeconomic and clinic data

\begin{tabular}{lrrrrl}
\hline Variables & n. $^{\circ}$ & Mean & Median & SD & KS \\
\hline Age & 84 & 63,40 & 64,50 & 14,190 & 0,470 \\
Education & 84 & 4,36 & 4,00 & 3,490 & 0,120 \\
Inocme per capita & 79 & 145,26 & 116,67 & 88,900 & 0,013 \\
Diagnosis time & 82 & 7,25 & 6,00 & 4,890 & 0,091 \\
Glicemia & 83 & 193,78 & 167,00 & 96,231 & 0,014 \\
IMC & 72 & 27,79 & 27,70 & 4,160 & 0,974 \\
Sistolic BP & 62 & 145,32 & 127,50 & 25,590 & 0,389 \\
Dyastolic BP & 62 & 85,55 & 87,00 & 10,320 & 0,024 \\
\hline
\end{tabular}


Table 2 - Sample distribution according to indicators of the nursing outcome Health Promotion Behavior and its final classification

\begin{tabular}{lcccc}
\hline Variables & Mean & Median & SD $^{1}$ & KS $^{2}$ \\
\hline Uses bahaviors to avoid risks & 3,86 & 4 & 0,690 & 0,000 \\
Monitors personal behavior regarding risks & 3,13 & 3 & 0,770 & 0,000 \\
Searches balance among exercise, work, rest and nutrition & 3,08 & 3 & 1,020 & 0,003 \\
Performs health habits correctly & 2,29 & 2 & 0,910 & 0,000 \\
Uses social support to promote health & 1,46 & 1 & 0,590 & 0,000 \\
Final classification of behavior of identified health promotion & 3,36 & 3 & 0,801 & 0,000 \\
\hline 1- Standard-deviation; 2 -Kolmogorov-Smirnov test & & & &
\end{tabular}

the indicator "Searches balance among exercise, work, leisure, rest, and nutrition", the ones that stood out were: proper nutrition (81.9\%), and rest and work $(79.8 \%)$. The proper exercise was identified in only $24.1 \%$. The percentile 25 presented two activities, showing that $75 \%$ of the sample performed at least two kinds of activities, "rarely" searching balance among exercise, work, leisure and rest and nutrition.

The indicator "Performs health habits correctly" presented a relatively low median value, since only two activities of this indicator had 5 points for, at least, half the sample. It corresponded in the scale to a correct "rarely" performing health habits .

Regarding the indicator "Uses social support to promote health", $71.4 \%$ of the sample mentioned the health care unit, while $63.1 \%$ searched their families or stayed at home during their problems. The community was searched by only $8.3 \%$ as well as only $3.6 \%$ decided to be part of a support group. These findings are confirmed by the median with value 1 for social support used. It indicated that at least half the sample looks over to 1 social support; "never shown" use of social support in the scale.

Regarding the "Final classification of identified health promotion behavior ", it is important to state that at least $8 \%$ of the sample presented "considerably" shown behavior, with standard deviation of 0.8 .

\section{DISCUSSION}

The proportion found among men and women in the gender variable is observed, analogically, by the data provided by the HiperDia Show which has 6,660 registered males and 18,150 females, in other words, 2.74 times higher ${ }^{(8)}$. They were grouped from May 2000 to May 2005 in the state of Ceará.

Furthermore, the average age of 63.4 years is in agreement with previous studies ${ }^{(12-13)}$. The BMI values also corroborate data from previous studies, which found $39 \%$ of individuals were overweight ${ }^{(12)}$. It is important to state that obesity, a chronic disease considered a public health issue in developed countries, is a defining characteristic among diabetes type 2 and hypertension patients due to the insulin resistance and hyperglycemia it causes. Thus, it is important, during clinic examination, to evaluate the relation between waist-hip and body mass index ${ }^{(11)}$.

The SAP and PAD results are compatible with the scientific literature that identified hypertension as the most present complication among individuals with diabetes $(70.9 \%)$ compared to other associated diseases ${ }^{(13)}$.

Regarding social support groups, it was observed that health units are a reference for non-registered clients. They also have educational services (day care center), recreation (swimming, water aerobics, stretching, and others) and professional courses. However, it was observed that the considerable search of the sample for only one kind of social support implies that there is little awareness about the social groups and little comprehension about health centered in medication.

Therefore, health promotion should be considered a responsibility of all areas, since governments cannot answer the social demands that determine health. One of the greatest challenges today consists of developing a healthier society, stimulating the planning of public policies capable to promote health, investing in studies and actions that improve the population's quality of life and stimulating their participation ${ }^{(14)}$.

\section{CONCLUSION}

It was observed that patients with diabetes followed by the researched institution still have limited health promotion practices. Therefore, there is a need for creating strategies that focus on transforming this reality in order to avoid possible complications from diabetes mellitus as well as other diseases.

The main difficulty found in implementing this study was the characterization of some health activities of the indicator "Searches balance among exercise, work, leisure, rest and nutrition". Some participants showed difficulties in distinguishing activities of leisure and rest where the same activity was differently defined among them. Another restrictive factor of the study was the lack of information or knowledge of the people regarding the indicator "Uses social support to promote 
health", since some saw "Support group" and "Community" as an equivalent for "Health unit". In order to minimize these two details, the participants who presented such difficulty refilled the form. In conclusion, further studies are necessary in order to better

\section{REFERENCES}

1. International Diabetes Federation. Diabetes prevalence [text on the Internet]. [cited 2006 Jun 10]. Belgium: IDF; c2003. Available from: http://www.idf.org.

2. Sociedade Brasileira de Diabetes - SBD. Dados sobre diabetes mellitus no Brasil [texto na Internet]. [citado 2006 Jun 17].Rio de Janerio:SBD; c2005. Disponível em: http:/ /www.diabetes.org.br .

3. Bezerra Barbosa R, Barceló A, Machado CA. Campanha nacional de detecção de casos suapeitos de diabetes mellitus no Brasil: relatório preliminar. Rev Panam Salud Publica = Pan Am J Public Health. 2001; 10(5): 318-27.

4. Buss PM. Promoção da saúde e qualidade de vida. Ciênc Saúde Coletiva. 2000; 5 (1): 163-77.

5. Pereira IMTB, Penteado RZ, Marcelo VC. Promoção da saúde e educação em saúde: uma parceria saudável. Mundo Saúde (1995). 2000; 24(1): 39-44.

6. Naidoo J, Wills J. Health promotion: foundations for practice. London: Baillière Tindall; 1998.

7. Johnson M, Maas M, Moorhead S, organizadoras. Classificação dos resultados de enfermagem (NOC). 2a ed. Porto Alegre: Artmed; 2004.

8. Brasil. Ministério da Saúde. Taxa de prevalência de diabete melito. Ministério da Saúde [texto na Internet]. [citado 17 Jun 2006]. Brasília (DF): Ministério da Saúde. Disponível characterize the population with DM regarding the health promotion actions based on NOC indicators within the different social contexts as well as the development of studies about interventions that may help to develop positive health behavior.

em: http://www.saude.gov.br.

9. Sociedade Brasileira de Hipertensão. Sociedade Brasileira de Hipertensão. Sociedade Brasileira de Nefrologia. V Diretrizes Brasileiras de Hipertensão Arterial. São Paulo: Sociedade Brasileira de Hipertensão; 2006.

10. Brasil. Ministério da Saúde. Secretaria de Atenção à Saúde. Coordenação Geral da Política de Alimentação e Nutrição. Guia alimentar para a população brasileira: promovendo a alimentação saúdavel. Brasília: Ministério da Saúde; c2005.

11. Vilar L, Castellar E, Moura E, Leal E, Machado AC, Teixeira L, Campos R. Endocrinologia clínica. Rio de Janeiro: Medsi; 2001.

12. Melo RP. Fenômenos de enfermagem identificados em pacientes diabéticos acompanhados numa unidade básica de atenção à saúde da família. Trabalho de Conclusão de Curso. (Graduação em Enfermagem). Fortaleza: Universidade Federal do Ceará; 2005. 56 f.

13. Rocha RM. Pé diabético: fatores comportamentais para a sua prevenção [tese]. Ribeirão Preto: Escola de enfermagem de Ribeirão Preto da Universidade de São Paulo; 2005.

14. Aerts D, Alves GG, La Salvia MW, Abegg C. Promoção de saúde: a convergência entre as propostas de vigilância da saúde e da escola cidadã. Cad Saúde Pública = Rep Public Health. 2004; 20 (4): 1020-8. 